\title{
Thoughts on Cultural Crisis and National Identity
}

\author{
Liping Sun \\ College of Mathematic and Information Science, QuJing Normal University \\ Qujing 655011, Yunnan, China \\ E-mail: jrslp219@yahoo.com.cn \\ Jiasheng Shi \\ College of Economics and Management, Yunnan Agricultural University \\ Kunming 650201, Yunnan, China
}

\begin{abstract}
At the Post-Cold War Era, western cultural hegemony came under question, and was replaced by cultural diversity. Cultural diversity is likely to result in cultural relativism, and might, as Huntington said, cause competition and clash among all civilizations, which will in turn lead to a global cultural crisis. Cultural crisis in China has changed with the period of time, and has not broken away from the sign of crisis so far. In this article, the authors will start from reflection upon the fever of "Sinology", and ponder over viewpoint by Mr. Yu Ying-shih on national identity. Then, the authors put forward their own view. That is, for national identity of China, it is still necessary to search for foundation in the cultural tradition of the three thousand years' history. Meanwhile, some new elements in the world should be integrated, which is the only way to avoid cultural crisis and work towards "modernization".
\end{abstract}

Keywords: Cultural crisis, National identity, Modernization

Since the Post-Cold War Era in the 1990s, the western mainstream consciousness headed by America came under question, and on the contrary, cultural diversity has received more universal recognition. In his $<<$ The Clash of Civilization and the Remaking of World Order $>>$, Huntington made a deep elaboration that pursuit of self cultural identity by all nationalities in the world had launched challenges to western cultural hegemony. It was not only a threat to western culture, but that various ethnic groups were formed in all nationalities. Cultural identities are different from each other, and cultural identity of each nationality has its strong exclusiveness. Therefore, multi-cultures mutually interweave with and affect each other. Competition and conflicts exist between different civilizations, and serious cultural crisis still underlies in the current world. In the spring tide of the world, cultural crisis in China has changed with time sequence, and still has not broken away from the sign of crisis.

\section{Reflection upon the fever of "Sinology"}

In the past few years, the fever of "Sinology" has appeared in China. Scholars undertaking humanistic studies have begun to seek for cultural identity from the tradition, and attempted to realize re-deconstruction on national identity, so as to break away from cultural crisis in China. Mr. Yu Ying-shih called this phenomenon "fundamentalism". At the same time, he also deeply pointed out that, study on "Sinology" in China was still in its infancy, and was still far away from being qualified to burden the task of Chinese history and culture. Generally speaking, similar to scientific research, humanistic research also calls for a long-term tradition of research as its base of foundation. The deeper the tradition of research, the more likely it is to get rid of the stale and bring forth the fresh. Humanistic research in western countries has had various variations in recent twenty or thirty years, but the entire tradition becomes more and more abundant. As for study on "Sinology", China established its profound foundation in the first half of the $20^{\text {th }}$ century. On one hand, China inherited the heritage of all parts of its traditional Classics, History, Philosophy, and Literary Collections. On the other hand, China has developed its own new viewpoint and methods, and orientation of its research is also polynary. A number of masters in traditional Chinese culture at that time, such as Wang Guowei, Chen Yanke, Qian Mu and Feng Youlan et al left behind abundant heritage. However, after 1950s, study on "Sinology" in China was enforced to be discontinued, so it might not be easy to resuscitate study on "Sinology" for the time being. A historiographer from Russia analyzed that, after the disintegration of Soviet Union, a "philosophical blankness" was left and "cultural 
vacuum" appeared in Russia. The old-fashioned traditional value system was criticized and even overthrown, and a new value system was not confirmed yet, so various ideologies were prevalent everywhere. Compared to Russia, there also existed "cultural vacuum" in China and Chinese people had no spiritual sustenance. Solitary and alienation of the spiritual world nowadays is more obvious than any period in the history as a result of the attack from the current market economy.

\section{Path choice for China to search for cultural identity}

At present, to seek for cultural identity and to re-deconstruct the value system in China is said to be a long way to go. However, what is certain is that search for cultural identity is absolutely not simply what "the Bring Principle" and "Fundamentalism" can resolve. Modernization in China needs to seek for its foundation in the cultural tradition of three thousand years in China. At the same time, new elements in the world should be integrated, which is the road we must take in order to avoid cultural identity and seek for national and cultural identity.

The famous Tang Dynasty Poet Du Mu said, "Each step of movement of a chessman in a chessboard should be determined by specific situation of that time, which cannot be predicted in advance. However, what is sure is that the chessman can never move out of the chessboard." Mr. Yu regarded "chessboard" as "traditional" external structure, and "chessman" as motive for internal development of the tradition. Before the $19^{\text {th }}$ century, all sorts of reformations of different scopes had happened within the tradition in China, and some were even quite vehement. However, that still didn't break through the fundamental traditional pattern, just as "chessman can never move out of the chessboard". At the end of the $19^{\text {th }}$ century, under attack of domestic and foreign power, traditional political system in China went into total disintegration. The feudal autocratic monarchy system with a long history of more than two thousand years in China was eliminated and the chessman has moved out of the chessboard. After the year 1911, if we say that political and economic system as "hardware" of "tradition" in China had already perished, then whether the "value system" as "software" of "tradition" had also perished? According to Mr. Yu, the value system as "software" had entered a state of "perishing, but not disappearing". The central idea of "three cardinal guides and five constant virtues" in Confucian thought was criticized by $<<$ Doctrine of Benevolence $>>$ (1896) by Tan Sitong, and was said to "perish" by the time of "May Fourth Movement". However, some individual values and concepts in the "tradition" did not and was unlikely to disappear immediately after they dissociated from the system of "tradition". This is the so-called "perishing, but not disappearing". These values and concepts not only stimulate and affect a lot of "modern" values and concepts, but also supplement each other. Hence, a quite important yet extremely eccentric degree of orientation is brought into form in the History of culture in China in the $20^{\text {th }}$ century. Research achievements by Mr. Yu have been known both at home and abroad. Reading articles by Mr. Yu can leave a deep impression upon people. Through the complex superficial image of the society, Mr. Yu can work out transitional threads in the culture in China. However, the viewpoint of the authors is a little bit different from the previous ideas of Mr. Yu. From the perspective of the authors, the "traditional" value system of China hasn't perished with collapse of the political system, and has also been far away from reaching the state of "perishing, but not disappearing". "Traditional" individual values and concepts dissociated from "traditional" system and stimulate with modern values and concepts, which is only the alienation of "tradition", or just a superficial phenomenon. However, as a matter of fact, its kernel still exists and plays a certain role. Only observation on the "life down at heel" of the common people can tell us something.

Here, the authors are going to talk about a story mentioned in $<<$ New Discussion on National History $>>$ (295) by Qian $\mathrm{Mu}$, the great master of Sinology, that there was a retired general who had gone through the Civil War in American. He had a bad temper and lived all his life in isolation. Each time he was in a bad mood, he would scold and beat whichever domestic servant he hired, so his servants came and left one by one. There was a man from Shangdong Province in China with the name of Ding Long, and he came to the general. However, the general still continued to scold and beat him when in a bad mood, so Ding Long also left out of anger. Several days later, the house of the general went on fire and Ding Long came back again. The general asked in surprise, "Why did you come back?" Ding Long answered, "I heard that your house was set on fire and you were in great need of hands for help. The Principle of Benevolence and Loyalty of Confucius is carried down from generation to generation, and I thought that I should come back". More surprised, the general said, "Confucius was a saint in China several thousand years ago. I did not know you have read and known about the principle by saints in your country." Ding Long said, "I am illiteracy and I haven't read any books. It was my father who taught me the principle". That general said, "Although you are illiteracy and haven not read, your father is a scholar." Ding Long continued, "Not yet, my father was not illiteracy and it was my grandfather who taught my father that principle. Even my grandfather was illiteracy and it was my great grandfather who taught that to my grandfather. Further beyond that, I also have no clear idea. In one word, all my ancestors had the class origin of farming but not reading." Extremely surprised, that general kept Ding Long at home and the master and the servant turned to friends. By the time when Ding Long was ill to death, he said to that general, "I have lived at your house for all my life. What I have eaten and used are yours, and you still give me salary. I have no home, relatives or friends, so all my money should be left here. Now, I am going to die, and I will return the money to you. Of course, this is supposed to belong to you." This general was even more amazed. He sent the remuneration Ding Long had left aside and another 
large sum of donation to Columbia University. He specially set up a course of lectures in the university for special study on Chinese culture. The lecture was called "Ding Long Lecture". That was the first special lecture set up in American universities for Chinese culture. As a matter of fact, Ding Long was not a saint, and so long as we go deeper into life of common people in China, we can find there are too numerous such cases to mention one by one.

Thereout, we come to a conclusion that, the "value system" of Chinese tradition does not mean perishing, but precipitating. These traditions have been inherited and accumulated from generation to generation in Chinese people, and it is not possible for them to be pulled up by the roots within several decades. They have just infiltrated into consciousness of human beings, and formed a cultural identity or national identity. Today, in order to realize Chinese modernization and re-deconstruct its value system, people have no other choice but to take "tradition" into consideration. Just as Mr. Yu said, the so-called "modern" was actually "modernization" of the "tradition" and "modernization" could go nowhere if it was dissociated from the subject of "tradition". Meanwhile, if China always held a unique and particular attitude in the world, it would be impossible to obtain general recognition from the entire world and to realize "modernization" in China. Unsuccessful integration into the world might result in other crises in addition to cultural crisis.

\section{References}

Qian, Mu. (2007). New Discussion on National History. Beijing: Sanlian Bookstore, 295-296.

Qin, Xiao et al. (2009). Summary of Informal Discussion on Social Transition and Modern Issues, in Reading. Beijing: Sanlian Bookstore, (7), 7.

Samuel P. Huntington. (1998). The Clash of Civilization and the Remaking of World Order. Beijing: Xinhua Press, 6.

Yu Ying-shih. (2005). Modern Crisis and Thinking Figures. Beijing: Sanlian Bookstore, 7, 9, 33. 